\title{
DETERMINATION OF RECENT MOVEMENTS OF LITHOSPHERE IN REGIONS WITH CHEMOGENIC SEDIMENTS ON THE SURFACE IN THE DINARIDES REGION
}

\author{
Almin Đapo, Boško Pribičević, Lidija Špiranec \\ University of Zagreb, Faculty of Geodesy, Croatia
}

\begin{abstract}
In the area of carbonate or karst Dinarides, besides the dominant carbonate rocks and subordinate clastics, in more places more significant mass of chemical sediments can be found, represented by gypsum and anhydrite. As chemical sediments are specifically lighter than overlying rocks, they have been, during the long geological history, trying to achieve isostatic equilibrium, or get out on the ground surface. In recent times, in areas with chemical sediments, a larger tectonic activity is noted than in the wider environment. This is certainly reflected in increased vertical and tangential displacements along major faults in relation to the surrounding area, which are built mainly of carbonate deposits. Determining the amount of movement of diapiric bodies, as absolute and relative, using the most modern surveying methods, precisely would assist the understanding of the tectonic movements and recent structural relations in a wider area.
\end{abstract}

Keywords: movement of diapiric bodies, surveying, tectonic movements

\section{Introduction}

The rocks in which karst systems develop are most commonly composed of carbonate, sulphate and chloride minerals. The sulphate minerals are quite numerous, but only gypsum and anhydrite form extensive masses in sedimentary sequences (Klimchouk\&Andrejchuk, 1996).

Gypsum is a common mineral (Fig. 1.), known also by its chemical name of hydrated calcium sulphate: CaSO $4 \times 2 \mathrm{H} 2 \mathrm{O}$. Gypsum crystallises in the monoclinic system, forming tabular and prismatic crystals. The mineral has a hardness of 2 and its density varies from 2.2 to $2.4 \mathrm{~g} / \mathrm{cm} 3$. Gypsum may form as granular, laminated, powdered, fibrous and radiate-fibrous aggregates. In crystals gypsum is normally colorless and transparent, but it sometimes has brownish colours. Compact masses 
of gypsum may be white, gray, pink, red, brown, pale yellow or pale blue; sometimes the gypsum is dotted or marble.

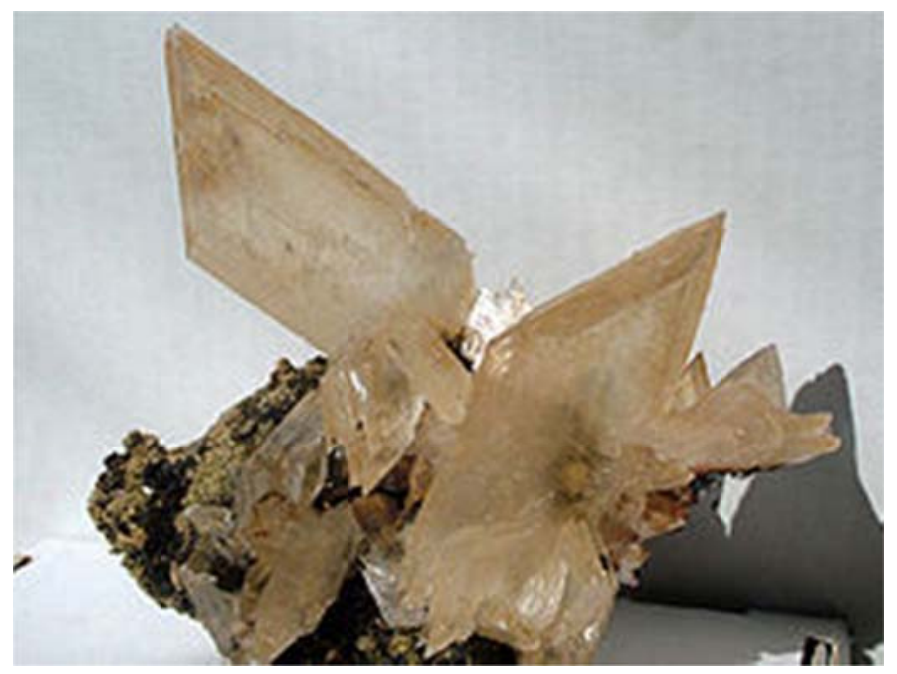

Fig. 1. Gypsum

Anhydrite (Fig. 2.) is the anhydrous form of calcium sulphate, CaSO4. Anhydrite crystals are rhombic with perfect cleavage along three orthogonal directions producing rectangular crystals. The hardness is 3.0 to 3.5 , and its density varies from 2.863 to $3.10 \mathrm{~g} / \mathrm{cm} 3$. Anhydrite commonly forms very compact fine-grained masses, but it also occurs as tabular, prismatic and fibrous aggregates. Common colours are white or pale shades of grey, blue, green, yellow, and red-brown.

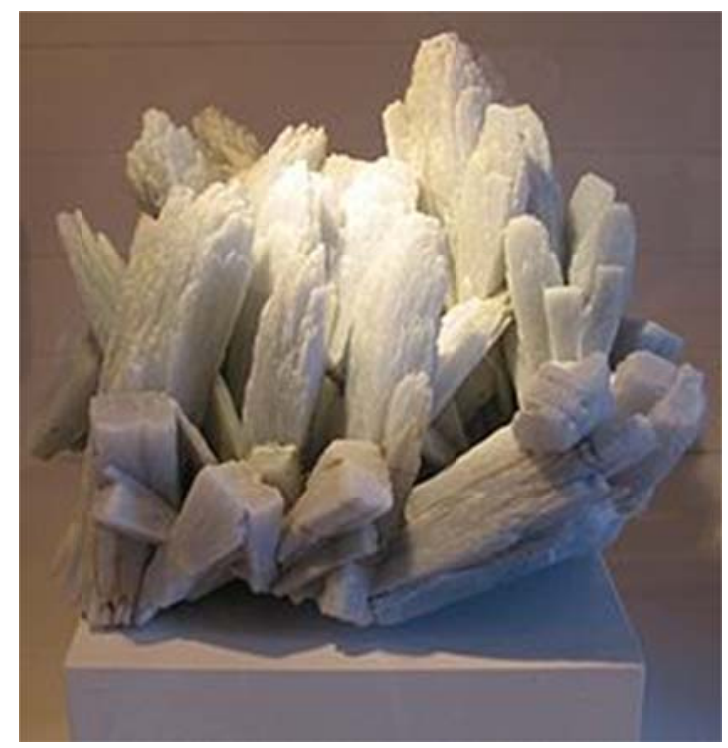

Fig. 2. Anhydrite

The stability of gypsum and anhydrite are considerably affected by changes in the physical and chemical parameters occurring within common geological environments. This results in hack and forth conversions between these minerals. It is widely believed that most gypsum has passed through the dehydration-hydration cycle. During the uplift phase, anhydrite frequently survives as masses at depths exceeding $100 \mathrm{~m}$, though the main masses of anhydrite are generally found at 
depths below 450 m (Jowett, Cathles-III \& Davis, 1993). In the upper zone of active groundwater circulation, sulphates are represented predominantly by gypsum. However, anhydrite is frequently dispersed, or preserved as local bodies within gypsum masses at quite shallow depths.

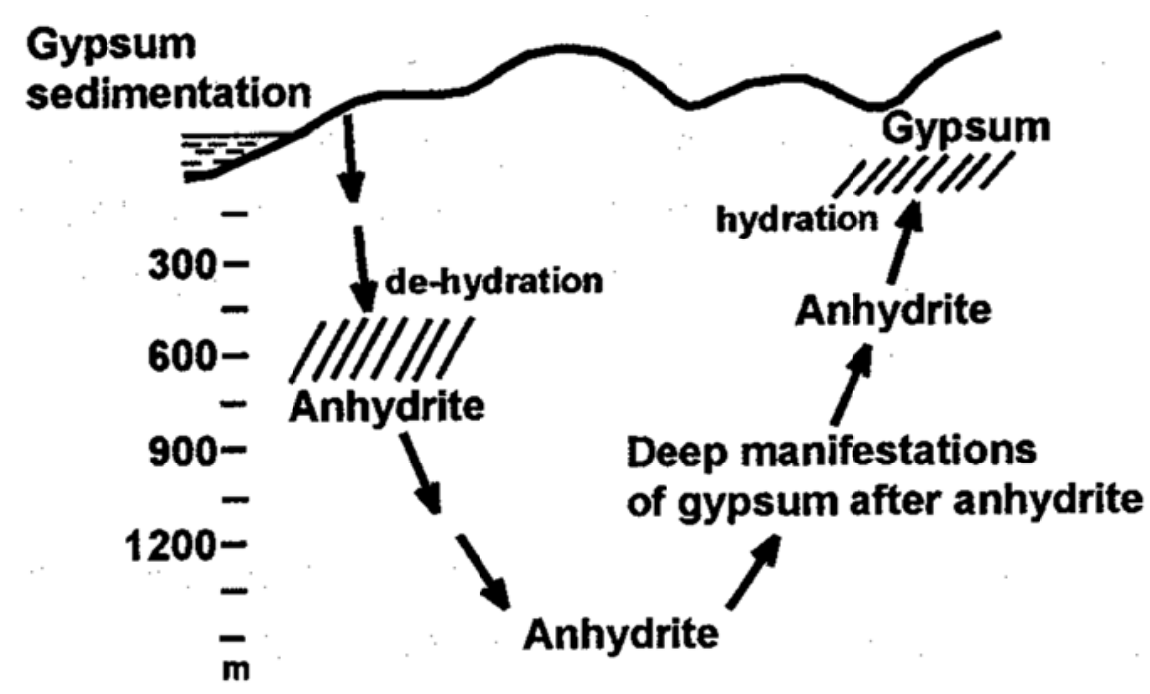

Fig. 3. Dehydration-hydration cycle of sulphate rocks (Murray, 1964)

As chemical sediments are specifically lighter than overlying rocks, they have been, during the long geological history, trying to achieve isostatic equilibrium, or get out on the ground surface. Since there is a connection between diapiric and salt tectonics and the development of oil and gas reservoirs, we decided to explore it more deeply in the area in central Croatia, the triangle between Knin, Drniš and Sinj. This area is specific for its geological structure with vast number of gypsum/anhydrite masses, as shown on the geological map of the research area (Fig. 4.).

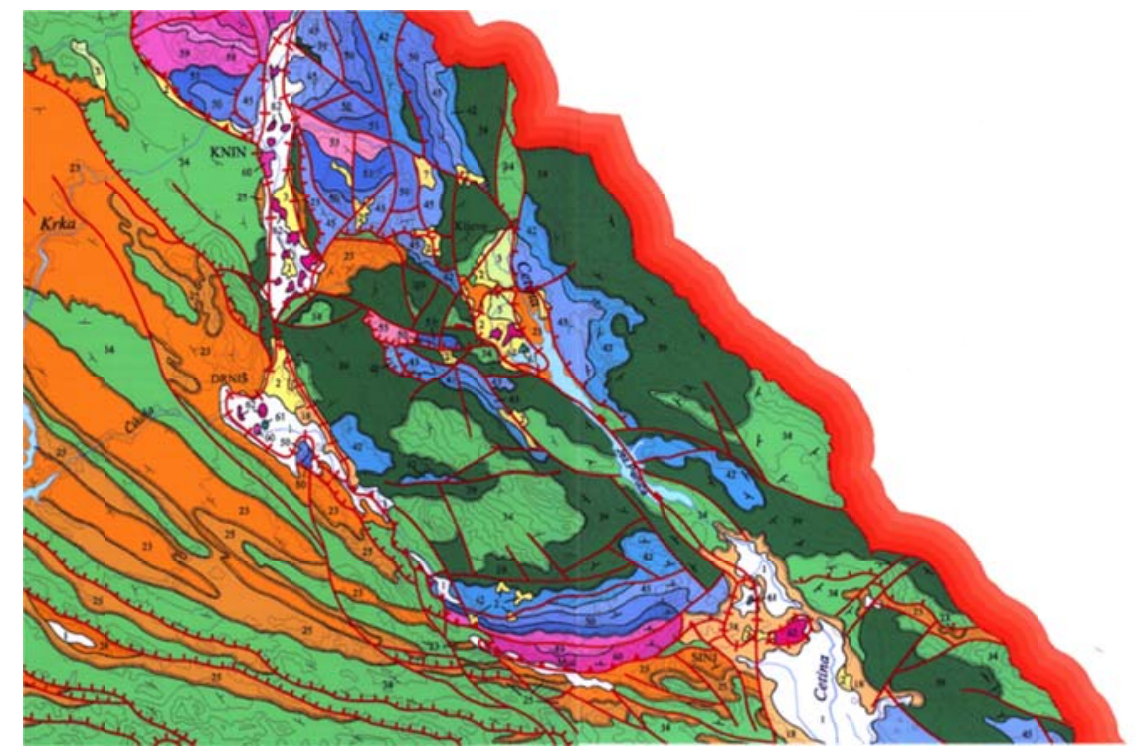

Fig. 4. Geological map of the research area

In recent times, in areas with chemical sediments, a larger tectonic activity is noted than in the wider environment. This is certainly reflected in increased vertical and tangential displacements along major faults in relation to the surrounding area, which 
are built mainly of carbonate deposits. Determining the amount of movement of diapiric bodies, as absolute and relative, using the most modern surveying methods, precisely would assist the understanding of the tectonic movements and recent structural relations in a wider area.

The idea is to track those movements, using the precise GPS technology. To be able to do this, the first step is to differentiate the "gypsum/anhydrite area" from the „rock area”. Afterwards, geodetic points have to be stabilized in both areas, to be able to monitor their shifts, both absolutely and relatively to each other. The final goal is to make a movement model, which could explain the past movements and predict the future ones.

\section{Methods and hypothesis}

According to the plan, four sets of geodetic points have been stabilized in the area of interest (Fig. 5.). The poins have special stabilization (Fig. 6.) that allows precise centering of the GPS antenna above the point with maximum accuracy.

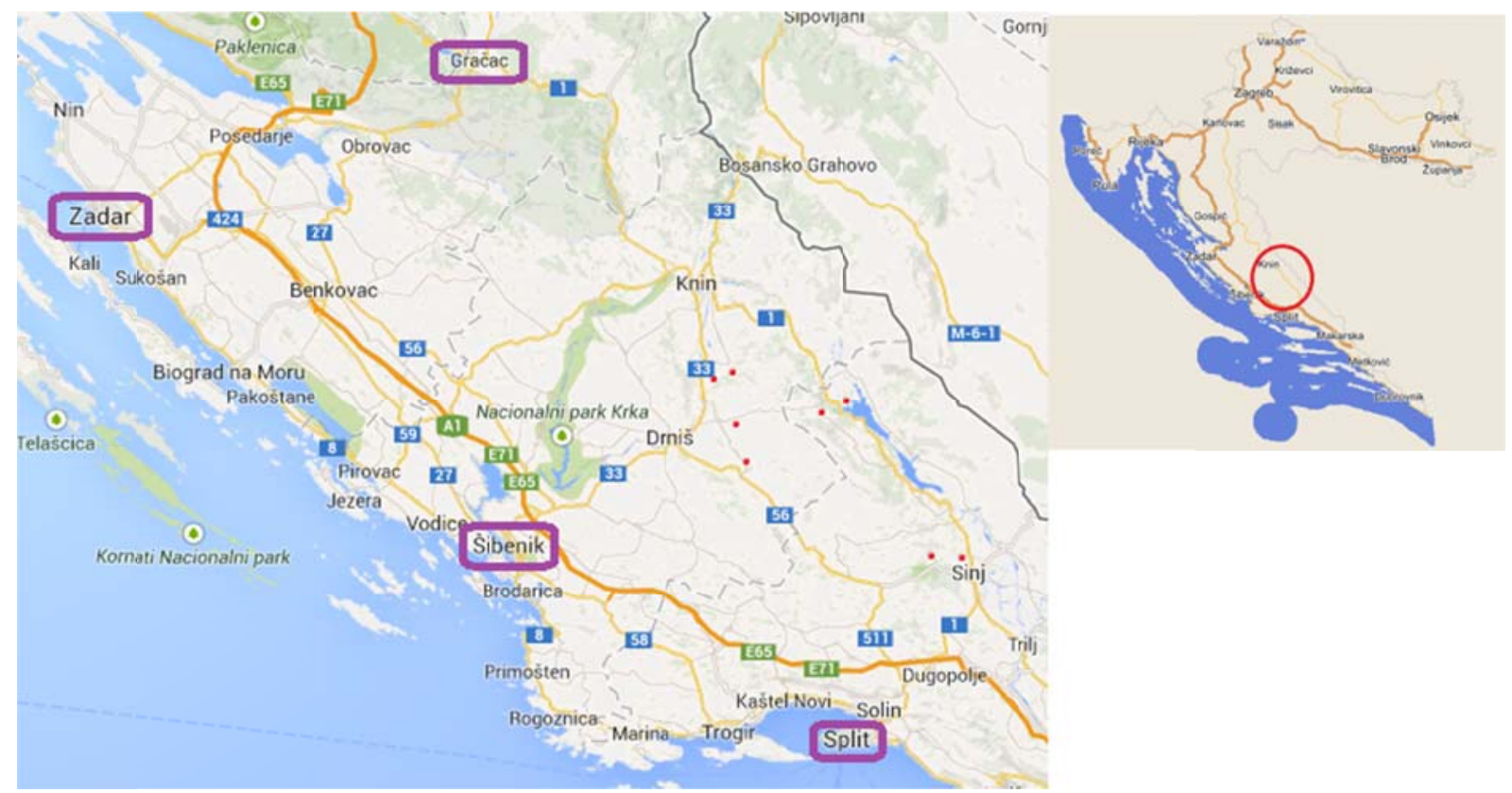

Fig. 5. The area of interest

Each set has one point in the carbonate area and one in the area with chemical sediments (Fig. 7.). This allows us to observe the local shifts between those two types of rocks. The hypothesis is that the area with chemical sediments tends to arise above the carbonate area due to its lower density. The assumption is that those shifts will be linear, which would enable us to compute and create a vertical movement model of chemical sediments.

The initial GPS campaign was completed in winter 2012, while second one is planned for this summer. The measurements were done on all 8 points simoultaneously, by Trimble R8 GNSS receivers in the period of 6 hours. During the computation and adjustment of coordinates, the points in the area, which are part of the CROPOS (Croatian Positioning System) network were fixed. Those were reference stations in Zadar, Šibenik and Split. The maps on the figure 5 represent the area of interest on the map of Croatia (red circle), and the position of stabilized points (red dots) and CROPOS reference stations (purple brackets). 
The results of the initial GPS campaign are shown in the Table 1. Estimated errors of coordinates of measured points are within $\pm 1.3 \mathrm{~mm}$.
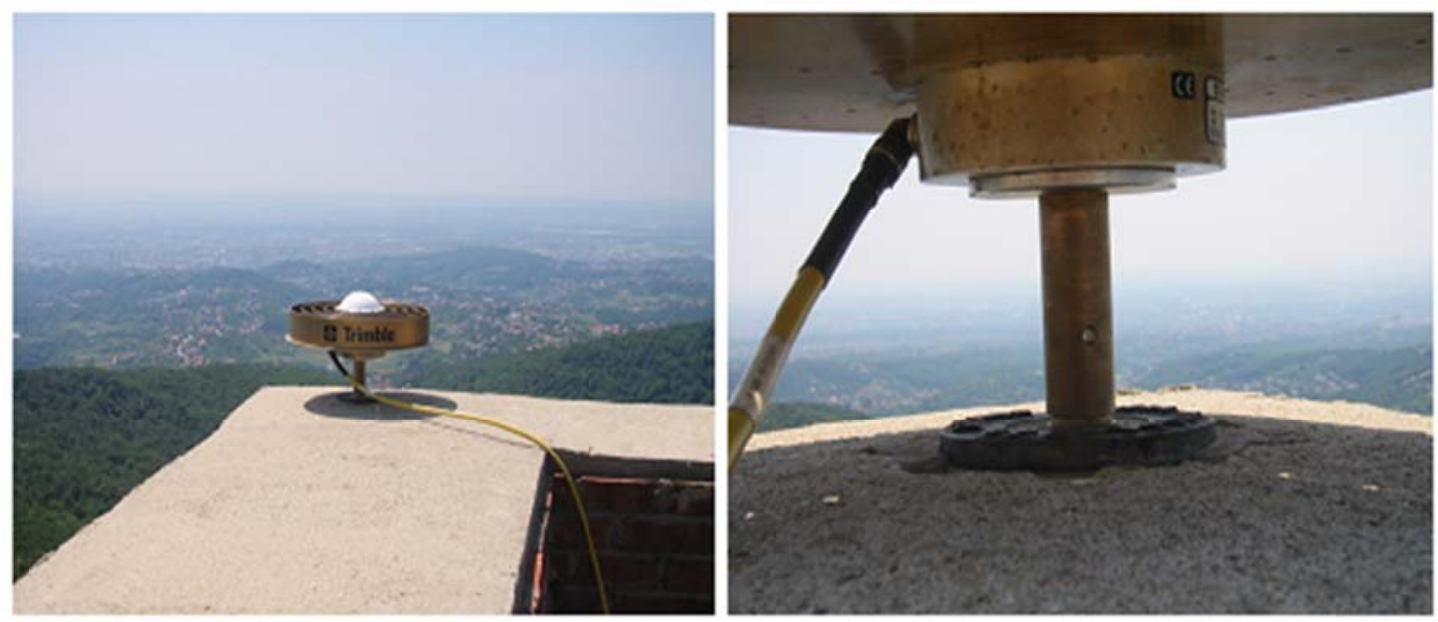

Fig. 6. Stabilisation of GPS antenna above the point (Đapo, 2009)
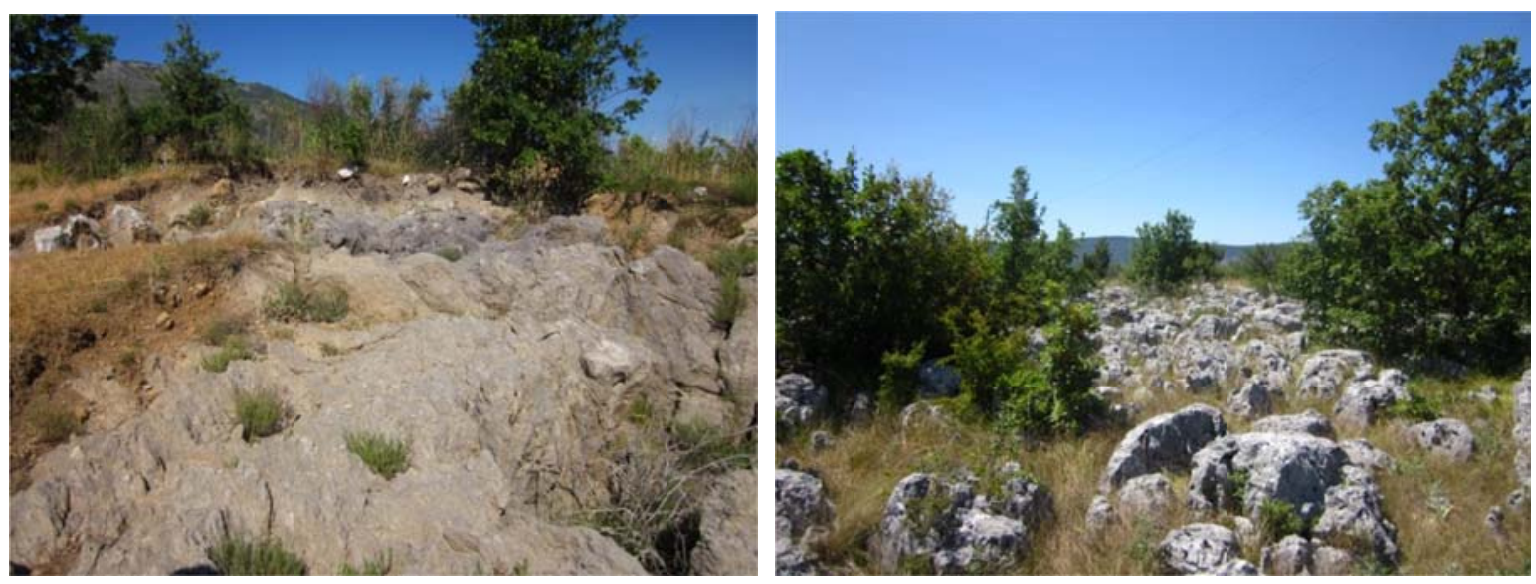

Fig. 7. Gypsum field near Drniš and anhydrite area near Vrlika

\section{Computation and visualisation}

The computer computation of GPS measurements is done using the GAMIT/GLOBK program package. It is a comprehensive suite of programs for analyzing GPS measurements primarily to study crustal deformation. The software has been developed by MIT, Scripps Institution of Oceanography, and Harvard University with support from the National Science Foundation. Representation and visualisation of the results will be made using Generic Mapping Tools - open source collection of about 60 tools for visualisation of results in geosciences, also supported by National Science Foundation.

GAMIT is collection of programs to process phase data to estimate threedimensional relative positions of ground stations and satellite orbits, atmospheric zenith delays, and earth orientation parameters. Input dana for GAIMIT are raw dana in RINEX format. The primary result of measurement processing is a loose solution in a form of $\mathrm{H}$-file, which includes estimated parameters and corresponding covariance, and is forwarded to GLOBK program. 
GLOBK is a Kalman filter whose primary purpose is to combine various geodetic solutions to acquire results. The role of GLOBK program is to combine the multisession data in order to get the location and speed of observed points, the covariance matrix and earth orientation and orbital parameters.

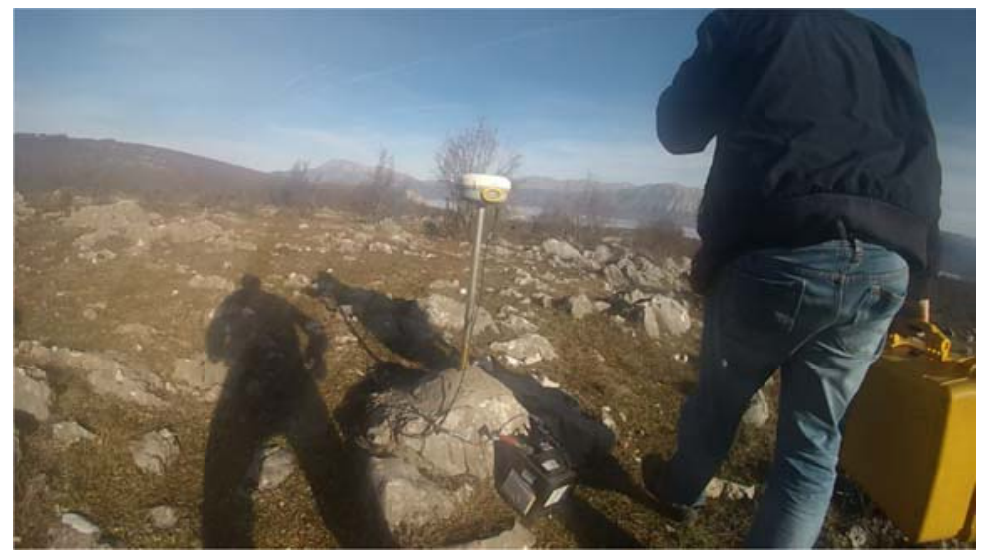

Fig. 8. GPS measurement on the point Maovice

Table 1. Results of the initial campaign

\begin{tabular}{|l|c|c|c|c|l|}
\hline Point name & $\mathbf{y}$ & $\mathbf{x}$ & $\mathbf{h}$ & $\begin{array}{c}\text { Formal } \\
\text { error }\end{array}$ & \multicolumn{1}{|c|}{ Type } \\
\hline pusto_groblje & 478255,50 & 4866069,87 & 323,41 & $\pm 0,9 \mathrm{~mm}$ & gypsum \\
\hline markovac & 480200,36 & 4867166,51 & 319,38 & $\pm 0,7 \mathrm{~mm}$ & rocks \\
\hline ruzic & 480333,13 & 4854706,42 & 317,52 & $\pm 1,1 \mathrm{~mm}$ & gypsum \\
\hline mircetic & 479147,69 & 4859859,42 & 454,12 & $\pm 0,6 \mathrm{~mm}$ & rocks \\
\hline maovice & 491307,56 & 4862145,03 & 680,50 & $\pm 1,3 \mathrm{~mm}$ & rocks \\
\hline peruca & 494950,76 & 4861905,17 & 419,67 & $\pm 1,0 \mathrm{~mm}$ & gypsum \\
\hline karakasica & 511378,35 & 4842281,34 & 420,05 & $\pm 0,2 \mathrm{~mm}$ & gypsum \\
\hline lucani & 508977,72 & 4842758,82 & 385,55 & $\pm 0,8 \mathrm{~mm}$ & rocks \\
\hline
\end{tabular}

\section{Conclusions}

If the hypothesis turns out to be correct and we conclude our research with a movement model of chemical sediments, one could be used to answer many seismological questions. Also, the model could help geologists in finding gas and oil, since chemical sediments are connected with their reservoirs. Since the structures caused by diapiric and salt tectonics play an important role in the development of oil and gas reservoirs, such a precise research could be used to estimate hydrocarbon saturation in a regional sense. 


\section{References}

Jowett, E. C., Cathles-III, L. M. \& Davis, B. W. (1993).Predicting depths of gypsum dehydration in evaporitic sedimentary basins. Amer. Assoc. Petrol. Geol. Bull., 77(3). pp. 402-413. Kempe, Chapter 11.5.

Đapo, A. (2009). Correlation of the Geodetic and Geologic Model of Tectonic Movement on the Example of the Wider Area of the City of Zagreb. University of Zagreb.

Klimchouk, A. \& Vjacheslav, A. (1996). Sulphate rocks as an arena for karst development. International Journal of Speleology, 25: pp. 9-20.

doi: http://dx.doi.org/10.5038/1827-806X.25.3.1

Murray R. C. (1964). Origin and diagenesis of gypsum and anhydrite. J. of Sedimentary Petrology, 34(3).

GAMIT and GLOBK home page at the Department of Earth Atmospheric and Planetary Sciences, MIT. Retrieved November, 2013, from http://www-gpsg. mit.edu/ simon/gtgk/

\section{Authors:}

doc. dr. sc. Almin Đapo ${ }^{1)}$, adapo@geof.hr prof. dr. sc. Boško Pribičević ${ }^{1)}$, bpribic@geof.hr Lidija Špiranec ${ }^{1)}$, mag.ing.geod. et geoinf, Ispiranec@geof.hr

1) University of Zagreb, Faculty of Geodesy, Kačićeva 26, Zagreb, Croatia 